\title{
PRÁTICA PEDAGÓGICA EM EDUCAÇÃO FÍSICA NOS ANOS INICIAIS DO ENSINO FUNDAMENTAL
}

\author{
Junior Vagner Pereira da Silva \\ Universidade Estadual de Santa Cruz, Ilhéus, Bahia, Brasil
}

\begin{abstract}
Resumo
Do tipo descritivo/exploratório, o estudo avaliou a prática pedagógica de professores de Educação Física, tendo como amostra 6 docentes dos anos iniciais do Ensino Fundamental que atuam na rede pública. Embora outros conteúdos sejam ministrados, os esportes coletivos tradicionais, sobretudo o futebol, predominaram. Em relação às estratégias metodológicas, apenas o estilo de ensino por tarefa foi utilizado. Conclui-se que, embora os esportes tradicionais sejam conteúdos importantes de serem trabalhados ao longo da formação básica, sua utilização excessiva contribuiu com a "monocultura" corporal do movimento. Em relação às estratégias metodológicas, conclui-se que as utilizadas pelos professores pouco contribuem com a formação crítica, criativa e autônoma dos alunos.
\end{abstract}

Palavras-chave: Educação Física e Treinamento. Currículo. Métodos.

\section{Introdução}

Tnserida na cultura de cada sociedade, a educação constitui-se num 1 processo formativo que ocorre em diferentes instituições sociais, classificadas em informais - família, igreja, associações, entre outras e formais - escolas (SILVA; DAGOSTIN; NUNEZ, 2009).

No âmbito escolar, a educação é responsável por duas facetas do processo formativo: a primeira se caracteriza pelo objetivo geral ao qual todos os professores, independente da área de atuação, devem estar comprometidos, que é a educação entendida como formação para a cidadania, para a adoção de posturas éticas e moralmente humanas, pois, conforme estabelece a Lei de Diretrizes e Bases da Educação Nacional no 9.394/96, em seu artigo $22^{\circ}$, a formação para o exercício da cidadania é uma das finalidades da Educação Básica (BRASIL, 1996). E esse Objetivo pode ser alcançado através da metodologia de 
ensino utilizada pelo docente. A segunda faceta diz respeito aos conhecimentos que cada componente curricular deve trabalhar, ou seja, trata-se dos objetivos formativos específicos de cada disciplina, que devem-se materializar através da sistematização dos conteúdos ao longo da formação básica.

$\mathrm{Na}$ Educação Física, uma das possibilidades (não a única) de trabalhar as questões formativas relacionadas aos valores éticos e morais (formação para a cidadania) é a utilização dos estilos de ensino "descoberta orientada" e "resolução de problemas", apresentados por Mosston (1982). Ainda, as estratégias de ensino "descoberta orientada" e "resolução de problemas" podem ser articuladas com as dimensões atitudinais dos conteúdos propostos por Zabala (1998) e retratados nos Parâmetros Curriculares Nacionais - PCN's (BRASIL, 1997, 1998), que têm como características o desenvolvimento de questões relacionadas à moral, à ética e aos valores humanos.

No que tange aos conhecimentos específicos da Educação Física, esses se darão via Cultura Corporal do Movimento que, além de ser organizado em conformidade aos conteúdos propostos nos PCN's jogos, esportes, lutas, ginástica, atividades rítmicas e conhecimento sobre o corpo (BRASIL, 1997, 1998), ainda podem ser ampliados com a agregação de novos conhecimentos, como as atividades corporais alternativas (COLDEBELLA; LORENZETTO; COLDEBELLA, 2004), atividades circenses (BORTOLETO; CALCA, 2007) e esportes radicais (PEREIRA; ARMBRUST, 2010).

Considerando as possibilidades formativas existentes a partir das aulas de Educação Física, os diferentes conhecimentos a serem desenvolvidos enquanto conteúdos e a importância da utilização de estratégias que oportunizem a participação crítica dos alunos, sobretudo na perspectiva de formação para autonomia, este estudo questiona: Quais conteúdos têm sido trabalhados nas aulas de Educação Física? Quais estratégias metodológicas de ensino têm sido utilizadas? As estratégias metodológicas de ensino utilizadas contribuem com o objetivo geral da educação básica de formação para a autonomia através do incentivo às ações críticas e criativas?

Diante do exposto, este estudo teve como objetivo analisar a prática pedagógica de professores de Educação Física nos anos iniciais do Ensino Fundamental. Especificamente investigou os conteúdos ministrados, avaliou as metodologias de ensino usadas e analisou se as me- 
todologias utilizadas favorecem a formação crítica, criativa e autônoma dos alunos.

\section{Metodologia}

O estudo configurou-se como descritivo/exploratório por analisar características de fatos e avaliar programas (MARCONI; LAKATOS, 2002), possibilitar a descoberta de práticas que necessitam ser modificadas e permitir a formulação de alternativas que possam substituir as já existentes (OLIVEIRA, 2002).

A população do estudo foi constituída por professores de Educação Física dos anos iniciais do Ensino Fundamental da rede pública municipal de ensino de Campo Grande, Mato Grosso do Sul, Brasil. Fizeram parte da amostra 6 professores que ministravam aulas de Educação Física nos anos iniciais do Ensino Fundamental (1o a 4o anos), vinculados a seis escolas.

A técnica de investigação adotada foi a observação sistematizada. Essa técnica de pesquisa consiste na examinação de fatos ou fenômenos que se pretende analisar, permitindo ao investigador um contato direto com o objeto de investigação e, quando desenvolvida de forma sistemática, exige um planejamento prévio e controlado do que se pretende observar, geralmente recorrendo ao uso de instrumentos como quadros, anotações, escalas, dispositivos mecânicos, dentre outros (MARCONI; LAKATOS, 2002).

Em relação ao que observar, Gil (2010, p. 104) recomenda que,

Na observação sistemática o pesquisador precisa elaborar um plano que estabeleça o que deve ser observado, em que momentos, bem como a forma de registro e organização das informações. O primeiro passo consiste em definir o que deve ser observado. Esta definição precisa levar em consideração os objetivos da pesquisa, o que significa que se estes não estiverem claramente definidos, será impossível conduzir adequadamente o processo de observação.

Ao todo foram observadas 72 aulas, sendo 12 por professor, ministradas em quatro turmas diferentes e acompanhadas em três semanas distintas. 
Como instrumento foi adotado um Diário de Campo, criado especificamente para acompanhamento da prática pedagógica de professores de Educação Física no âmbito escolar. No tratamento dos dados recorreu-se à análise estatística descritiva (frequência absoluta).

O estudo atendeu as recomendações da Resolução no 196/96, do Conselho Nacional de Saúde, para estudos com Seres Humanos e Animais. Os participantes foram previamente esclarecidos sobre o estudo e deles se obteve a aceitação em participar, por intermédio da assinatura do Termo de Consentimento Livre e Esclarecido, e o estudo foi aprovado pelo Comitê de Ética em Pesquisa e registrado sob o no 097/Anhanguera-Uniderp.

\section{Resultados e discussão}

Os dados relacionados aos conteúdos trabalhados nas aulas de Educação Física indicam que os esportes figuram como predominantes, sobretudo, o futebol e o voleibol, conforme pode ser visualizado no quadro 1. Embora os jogos tradicionais tenham sido realizados na maioria das escolas, o mesmo não ocorreu com outros jogos importantes para o desenvolvimento infantil - jogos simbólicos e rodas cantadas. Ainda, conteúdos como a ginástica (artística, rítmica e localizada), as danças, o handebol, o atletismo e os jogos de construção não foram trabalhados em nenhuma das aulas observadas.

Tabela 1: Conteúdos trabalhados nas aulas de Educação Física

\begin{tabular}{|c|c|c|c|c|c|c|}
\hline & \multicolumn{6}{|c|}{ Quantidade de aulas } \\
\hline & Escl & Esc2 & Esc 3 & Esc4 & Esc5 & Esc6 \\
\hline Voleibol & & 1 & 9 & 7 & & \\
\hline Basquetebol & & & & & 1 & \\
\hline Futsal/futebol & 12 & 2 & 9 & 12 & 5 & \\
\hline Pré- desportivos & & & 2 & & 10 & 3 \\
\hline Jogos simbólicos & & 2 & & & 1 & \\
\hline Jogos tradicionais & & 7 & 3 & 8 & & 5 \\
\hline Ginástica escolar & & 1 & & & & 2 \\
\hline Rodas cantadas & & 5 & & & & \\
\hline Conhec. sobre o corpo & & & & & & 2 \\
\hline Atividades em sala & & 1 & & & & 3 \\
\hline Jogos de Salão & 12 & & 10 & & & \\
\hline
\end{tabular}

Legenda: Esc - Escola

A predominância dos esportes como conteúdo nas aulas de Educação Física também tem sido evidenciada em outras localidades brasileiras, seja nos anos iniciais (ARAÚJO; ROCHA, 2007; 
FILGUEIRAS et al., 2007; SOARES et al., 2010) ou finais (BEGIATTO; SILVA, 2007; COSTA; NASCIMENTO, 2006; PERFEITO et al., 2008; ROSÁRIO; DARIDO, 2005) do Ensino Fundamental. Estudo de revisão sobre os conteúdos ministrados nos anos iniciais e finais do Ensino Fundamental evidenciou que, dos 24 artigos analisadas, os esportes tradicionais (futebol, voleibol, basquetebol e handebol) predominaram em 18 (SILVA; SAMPAIO, 2012).

A manifestação dos esportes coletivos como principais conteúdos da Educação Física, a exemplo dos estudos brasileiros, também foi observada em outras localidades da América do Sul - La Plata, Argentina (PATRÍCIO; SARAIVA; BERGERO, 2009), Bogotá, Colômbia (GUTIÉRREZ; MARIN; ORTIZ, 2010), Huelva, Colômbia (RODRIGUEZ; FUENTES-GUERRA; ROBLES, 2010) e da Europa - Espanha (VALENZUELA; BUENO, 2010).

Além de predominar como conteúdos, pesquisas dão conta de que os esportes tradicionais figuram entre os preferidos pelos alunos nos anos iniciais (FILGUEIRAS et al., 2007) e finais (BEGGIATO; SILVA, 2007; BENTO; RIBEIRO, 2008) do Ensino Fundamental, assim como se manifestam como uma das principais atividades fisicamente ativas realizadas no cotidiano extraescolar de crianças e adolescentes brasileiros (GARCIA; FISBERG, 2011; LIMA; STAREPRAVO, 2010), espanhóis - Madri e Granada (GARZÓN et al., 2002), espanhóis (MORENO; RODRÍGUEZ; GUTIÉRREZ, 2003), colombianos - Huila (PARRACI et al., 2010) e chilenos (GARRIDO et al., 2011).

A predominância dos esportes como conteúdo das aulas de Educação Física e uma das principais atividades fisicamente ativas de lazer pode estar relacionada ao fato de os esportes se manifestarem como um dos mais importantes fenômenos sociais do século XX (MOREIRA, 2002) e uma das mais representativas expressões sociais contemporâneas (GAYA, 2006), em que a Copa do Mundo de Futebol e as Olimpíadas figuram como principais representações simbólicas, quando bilhões de pessoas deixam parte dos seus afazeres cotidianos para prestigiarem seus ídolos.

Contudo, diferentemente do observado em outros países sul-americanos, como Colômbia, onde a ginástica, o basquetebol e o voleibol predominaram nas aulas de Educação Física - Bogotá (GUTIÉRREZ; MARIN; ORTIZ, 2010) e o voleibol, basquetebol e handebol - Huelva (RODRIGUEZ; FUENTES-GUERRA; ROBLES, 2010) e Chile, onde o atletismo se mostrou como conteúdo mais prestigiado (FREUNDT, 
2010), no Brasil, o futebol figura como conteúdo mais aplicado entre os esportes tradicionais, condição que pode estar ocorrendo devido à relação existente entre o futebol e a cultura brasileira, afinal, essa modalidade é a mais popular em nosso país, o que faz com que este figure como fator gerador de identidade e um dos principais patrimônios culturais nacional.

Sobre essa questão Gastaldo (2003, p. 8) também corrobora, salientando que,

mesmo sem negar que a mítica do "país do futebol" seja resultado de um processo histórico e social que não tem mais de 50 anos, este esporte é hoje um dos principais emblemas da "identidade brasileira", juntamente com o samba e as chamadas "religiões afrobrasileiras $[\ldots] "$ ".

Desta forma, cabe ressaltar que os esportes tradicionais, dentre eles o futebol, configuram-se em importantes conteúdos da Educação Física, devendo sua aplicação não ser negada, uma vez que se trata de conhecimentos de uma cultura a ser reproduzida, transformada, ampliada e pedagogizada ao longo da formação básica, mas sim sistematizada, através de sua tematização, possibilitando que diversas nuances sobre a sua prática, contemplação ou assistência sejam discutidas, favorecendo não a sua negação no âmbito escolar, mas a vivência, o conhecimento, a análise crítica e reflexiva sobre sua construção social.

Souza Júnior e Darido (2010), atentos às possibilidades educacionais através da tematização dos esportes, apresentam uma interessante proposta de trabalho para o futebol nas aulas de Educação Física, superando o deixar fazer "rolar a bola" e a limitação do ensino dos aspectos técnicos. Nesse trabalho, os autores sugerem que o futebol seja estruturado em nove temas - Dimensões sociais do esporte - educação, participação e rendimento; A origem do futebol; Futebol e cultura escolar; Futebol no Brasil; Futebol e arte; Fundamentos técnicos do futebol; Futebol e ética; Futebol feminino e o seu contexto; Resgate de jogos da cultura popular; Futebol feminino e o seu contexto e Resgate de jogos a cultura popular.

Além dos temas propostos pelos autores, acreditamos na possibilidade de incrementação da proposta com a inserção de mais alguns temas, como: Esporte e mídia (discussão sobre a influência da mídia 
sobre o esporte - adesão e mudanças de regras; análise dos esportes vinculados aos programas esportivos); Esporte e mercado de trabalho (escolinhas de esporte, seleção de jogadores infantis, salários de atletas, percentuais de atletas que recebem salários milionários); Esporte e tecnologias (uso da tecnologia aplicada ao rendimento no esporte); Esporte e política (uso do esporte como forma de alienação), dentre outras possibilidades que podem pelos criadas por professores e alunos, no contexto escolar.

Por outro lado, não se pode negar a importância da ampliação dos conteúdos trabalhados nas aulas de Educação Física, pois isso pode favorecer crianças e adolescentes, que não apreciam os esportes tradicionais (futebol, voleibol, basquetebol e handebol), a ocuparem seu tempo de lazer com outras atividades físicas, como jogos simbólicos, jogos de construção, rodas cantadas, ginástica (artística, rítmica e localizada), danças (urbanas, regionais, contemporâneas), lutas, atletismo, atividades de aventura, esportes radicais, dentre outras formas de manifestação da cultura corporal do movimento, dado que os desejos e os gostos humanos são os mais diversos.

Dito de outra forma, devemos estar atentos ao fato de que, embora os esportes tradicionais figurem como uma das maiores manifestações humanas e, em especial, entre os brasileiros, o futebol, há aqueles que, mesmo gostando dessas modalidades, também anseiam vivenciar e aprender outros conteúdos. Assim como há os que não gostam e têm seu interesse despertado por outras atividades.

Ainda, a constituição de uma "monocultura corporal" pode levar alunos que não têm interesse ou não gostam das modalidades esportivas tradicionais a se afastarem das aulas de Educação Física e, consequentemente, das atividades físicas/esportivas no cotidiano, uma vez que, segundo Darido (2004), a adoção de um estilo de vida sedentário por parte dos alunos que se sentiram desmotivados nas aulas de Educação Física devido à limitação dos conteúdos, pode ser consequência de não encontrarem mais prazer nessas atividades. De acordo com Bocarro e Forrester (2008), em direção oposta caminham aqueles que vivenciam experiências esportivas diferenciadas na infância e adolescência, podendo exercer impactos positivos na adesão e manutenção da atividade física ao longo da vida.

Contudo, é importante ressaltar que a limitação das aulas de Educação Física aos esportes tradicionais não se configura no único problema relacionado à prática pedagógica, porque a forma com que 
esses conteúdos são trabalhados pelo docente é condição essencial para compreender o comprometimento de suas aulas com a formação dos alunos para o exercício da cidadania e ação autônoma na sociedade. Desta forma, a metodologia utilizada pelos professores participantes deste estudo foi avaliada, por intermédio do estilo de ensino utilizado, e, conforme Clavellinas (2011, p. 6), os estilos de ensino adotados configuram-se como

forma peculiar de interaccionar con los alumnos y que se manifiesta tanto en las decisiones preactivas, durante lãs decisiones interactivas y en las decisiones postactivas. Según el estilo de enseñanza que adopte el profesor, éste se relacionará con los distintos elementos del acto didáctico de una forma que marcará las propias relaciones con los mismos.

A respeito das metodologias usadas no ensino/aprendizagem dos conteúdos, identificou-se que, em todas as escolas e aulas, os professores se valeram do estilo de "ensino por tarefas", no futsal/futebol, voleibol e basquetebol ocorreram pelo "ensino dos fundamentos técnicos" e nos demais conteúdos pelo "deixar jogar".

Tabela 2: Estilos de ensinos utilizados nas aulas de Educação Física observadas

\begin{tabular}{|c|c|c|c|c|c|c|}
\hline Escolas & Comandos & Tarefas & $\begin{array}{l}\text { Avaliação } \\
\text { Recíproca }\end{array}$ & $\begin{array}{l}\text { Programação } \\
\text { Individualizada }\end{array}$ & $\begin{array}{l}\text { Descoberta } \\
\text { Orientada }\end{array}$ & $\begin{array}{l}\text { Resolução de } \\
\text { Problemas }\end{array}$ \\
\hline Escola 1 & & $\mathrm{x}$ & & & & \\
\hline Escola 2 & & $\mathrm{x}$ & & & & \\
\hline Escola 3 & & $\mathrm{x}$ & & & & \\
\hline Escola 4 & & $\mathrm{x}$ & & & & \\
\hline Escola 5 & & $\mathrm{x}$ & & & & \\
\hline Escola 6 & & $\mathrm{x}$ & & & & \\
\hline
\end{tabular}

Legenda: $\mathrm{x}$ - escolas em que o estilo de ensino foi utilizado nas aulas

Os dados obtidos neste estudo a respeito do estilo de ensino adotado são similares aos observados em segmentos não escolares desenvolvendo atividades esportivas (natação, ginástica olímpica e futebol) em Campinas, SP (GOZZI; RUETE, 2006), artes marciais chinesas no Brasil (ANTUNES; MOURA, 2010) e segmentos escolares do $1^{\circ}$ e $2^{\circ}$ ciclos do Ensino Fundamental de uma escola privada de uma cidade do interior de São Paulo, Brasil (GOZZI; RUY, 2008) e Valpa $\neg$ raíso y Viña del Mar, Chile (ALARCÓN; REYNO, 2004), que evidenciaram o "ensino por tarefa" como predominante. No entanto, diferencia-se 
das observações de aulas realizadas no ensino fundamental de duas escolas municipais do Rio de Janeiro, RJ, quando foi verificado, nas aulas práticas, o predomínio do estilo de ensino "por comando" (MOURA, 2009).

Verifica-se, assim, que as estratégias de ensino utilizadas nas aulas observadas revelam dados preocupantes, visto que, embora o estilo de "ensino por tarefas" possibilite maior desenvolvimento nos canais físico, social, cognitivo e motor, quando comparado ao "ensino por comando" essa metodologia ainda se fundamenta em modelos pré-estabelecidos, centralizados no professor (GOZZI; RUETE, 2006), geralmente pautado em princípios de exclusão, uma vez que só existe espaço para a realização de movimentos dados como ideais, principalmente quando eles são fundamentos técnicos de uma modalidade esportiva, realizados, sobretudo, de forma analítica, fragmentada e repetitiva, pouco permitindo a reflexão e a participação autônoma dos alunos nas decisões, como evidenciado em nossa investigação e em estudos brasileiros realizados em Salvador, BA (ARAÚJO; ROCHA, 2007) e Rio de Janeiro, RJ (SOARES et al., 2010), e também observado nas aulas de Educação Física em Murcia, Espanha (TOMÁS et al., 2010). Ainda, as exigências padronizadas de movimentos nas aulas de Educação Física têm contribuído para que "gozações" e estereótipos ocorram contra aqueles que não conseguem se adequar aos padrões estabelecidos, resultando em evasão das aulas devido aos constrangimentos e às agressões sofridas, conforme mostrou resultado de pesquisa realizada por Paiano (2006).

Entende-se que, além de sistematizar seus conteúdos ao longo da formação básica, também compete à Educação Física criar situações para que o aluno atue de forma crítica e reflexiva, no entanto, constata-se que as aulas analisadas pouco contribuíram nesse sentido, dado que não foi evidenciada, em nenhuma atividade, a utilização de estratégias como a "descoberta orientada" e/ou "solução de problemas", estilos de ensino que favorecem e estimulam a autonomia dos alunos.

Embora as decisões ainda sejam centradas no professor, sobretudo no planejamento dos passos a serem aplicados para levar o aluno à descoberta, no estilo de ensino "descoberta orientada" há maior desenvolvimento dos canais cognitivo e moral, uma vez que os questionamentos realizados pelo professor provocam uma sequência de reflexão e busca de respostas que contemplem os questionamentos, ou 
seja, o aluno descobre novos conceitos, resultando em maior desenvolvimento no canal emocional (GOZZI; RUETE, 2006).

Quanto à utilização do estilo de ensino por solução de problemas, pode ocorrer de duas formas: convergente e divergente. Na "solução de problemas divergentes", a partir da criação de situações-problema pelo professor, o aluno busca uma única resposta para o problema criado e toma uma decisão, proporcionando que maior desenvolvimento ocorra nos canais físico, cognitivo e moral. Já na "solução de problemas divergentes", a partir de um problema lançado pelo professor, os alunos buscam diferentes possibilidades que podem responder a um mesmo problema, favorecendo, com isso, que haja maior desenvolvimento nos canais social, cognitivo, moral e emocional (GOZZI; RUETE, 2006).

O estilo de ensino resolução de problemas constitui-se em uma 'irritação cognitiva' provocada pelo professor, por meio de uma nova atividade ou de sua ajuda aos alunos, cujo objetivo é incentivar esses alunos, por intermédio de perguntas, a refletir e a buscar soluções. Parte de uma situação inicial que estimula e aguça a curiosidade do educando via situações didáticas, que, a fim de uma formação autônoma, podem ser criadas pelo professor ou pelos próprios alunos (FARIA JUNIOR; CORREA; BRESSLANE, 1987), ou seja, o problema "[...] permite a descoberta, a partir de elementos de base conhecidos (pesquisa de variantes a partir do ensino de uma dificuldade) [...], debates entre os alunos ou entre os alunos e o professor, com o objetivo de provocar reflexões e evocações" (MOSSTON, 1982, p. 16).

\section{Conclusão}

Conclui-se que os esportes tradicionais configuram-se nos principais conteúdos trabalhados nas aulas de Educação Física observadas, predominando, entre eles, o futebol e o voleibol, e, desse modo, favorecendo a ocorrência de uma monocultura corporal do movimento, haja vista que conteúdos como ginástica, danças, atletismo e jogos de construção não foram trabalhados em nenhuma das aulas observadas.

Em relação às estratégias metodológicas, a observação das aulas indicaram que os docentes utilizaram unicamente o estilo de ensino "por tarefa" e isso permite concluir que essas aulas pouco têm contribuído com a formação para a autonomia e a ação crítica e criativa dos 
alunos, uma vez que as aulas têm sido pautadas na reprodução de gestos esportivos ou no puro ato de jogar.

Por fim, cabe ressaltar que, embora haja necessidade de ampliação dos conteúdos trabalhados nas aulas de Educação Física, não se nega a importância da presença dos esportes coletivos nessas aulas, mas sim se critica a restrição a eles, como também a utilização de, apenas, estratégias metodológicas que não valorizam a participação crítica dos alunos. Desta forma, vislumbramos a urgência de mudanças tanto na ampliação dos conteúdos quanto na utilização de metodologias de ensino que discutam questões sociais, éticas, motoras e metodológicas dos esportes e das demais manifestações da cultura corporal do movimento, favorecendo não somente a reprodução de movimentos, mas também um processo educativo que oportunize sua incorporação ao longo da vida.

Pedagogical practice in physical education in the early grades of elementary school

\begin{abstract}
A descriptive/exploratory study the pedagogical practice of physical education teachers, six teachers with a sample of the lower grades of primary education in public schools that operate in Campo Grande/MS. The results indicate that while other content Will also be taught the traditional team sports, especially football, predominate. In relation to teaching styles, only a task is used. We conclude that although the traditional sports are important content to be worked through basic training, their overuse hás contributed to the formation of a "monoculture" of body movement. In relation to teaching style, it is concluded that the strategies used by teachers contribute little to the formation critical, creative and independent students.
\end{abstract}

Keywords: Physical Education. Content. Teaching style.

Práctica docente en educación física en los primeros años de la escuela primaria

\title{
Resumen
}

Este es un estudio descriptivo / exploratorio evaluar la práctica pedagógica de los profesores de educación física, los maestros con una muestra de seis años de escuela primaria que trabajan en público en Campo Grande / MS. Aunque el contenido de otros también se les da, se encontró que los deportes de equipo tradicionales, especialmente el fútbol, predominan. En relación con los estilos de enseñanza, sólo por la tarea que se utiliza. Llegamos a la conclusión de que a pesar de los deportes tradicionales son contenidos importantes para ser trabajado a través de la formación básica, su uso excesivo ha contribuido a la formación de un "monocultivo" del 
movimiento del cuerpo. Con respecto al estilo de enseñanza, se concluye que las estrategias utilizadas por los profesores contribuyen poco a la formación de estudiantes críticos, creativos e independientes.

Palabras clave: Educación Física. Contenido. Estilo de enseñanza.

\section{Referências}

ALARCÓN, T.; REYNO, A. Estilos de enseñanza de la Educación Física en la Enseñanza Media municipalizada de las ciudades de Valparaíso y Viña del Mar (Chile). Revista de Ciencias de la Actividad Física, Playa Ancha, v. 12, n. 23, p. 33-58, 2004.

ANTUNES, M. M.; MOURA, D. L. A identificação dos estilos de ensino dos professores das artes marciais chinesas (wushu) no Brasil. Pensar a Prática, Goiânia, v. 13, n. 3, p. 1-18, set./dez., 2010.

ARAÚJO, A. DE A.; ROCHA, L. C. A atuação dos professores de educação física na escola: uma investigação dos aspectos das aulas de educação física escolar no ensino público de Salvador. Diálogos possíveis, Salvador, v. 6, n. 1, p. 175-187, 2007.

BEGGIATO, C. L.; SILVA, S. A. P. dos S. Educação Física Escolar no ciclo II do ensino fundamental: aspectos valorizados pelos alunos. Motriz, Rio Claro, v. 13, n. 2 (Supl. 1), p. S29-S35, maio/ago., 2007.

BENTO, L. C. M.; RIBEIRO, R. D. As aulas de Educação Física na concepção dos alunos de $5^{\mathrm{a}}$ a $8^{\mathrm{a}}$ série do ensino fundamental da cidade de Indianópolis - MG. Motrivivência, Florianópolis, ano 20, n. 31, p. 354-368, dez., 2008.

BOCARRO, J.; FORRESTER, S. School physical education, extracurricular sports, and Lifelong active living. Journal of Teaching in Physical Education, v. 27, n. 2, p. 155-166, abr., 2008.

BORTOleto, M. A. C.; CAlCA, D. H. Circo e educação Física: compendium das modalidades aéreas. Movimento \& Percepção, Espírito Santo do Pinhal, v. 8, n. 11, p. 345-360, jul./dez., 2007.

BRASIL. Lei de Diretrizes e Bases da Educação Nacional. Lei 9.394/96, de 20 de dezembro de 1996. Brasília: MEC/SEF, 1996. 
BRASIL. Parâmetros Curriculares Nacionais: Educação Física Séries Iniciais. Brasília: MEC/SEF, 1997.

BRASIL. Parâmetros Curriculares Nacionais: Educação Física Séries Finais. Brasília: MEC/SEF, 1998.

CLAVELLINAS, J. J. M. De La Educación Física hacia La educacíon física bilíngüe: um análisis desde el punto de vista metodológico. EmásF - Revista Digital de Educación Física, ano 2, n. 10, p. 10-19, maio/jun., 2011.

COLDEBELlA, A. de O. C.; LORENZETTO, L. A.; COLDEBELLA, A. Práticas Corporais alternativas: formação em Educação Física. Motriz, Rio Claro, v. 10, n. 2, p. 111-122, maio/ago., 2004.

COSTA, L. C. A.; NASCIMENTO, J. V. Prática pedagógica de professores de Educação Física: conteúdos e abordagens pedagógicas. Revista da Educação Física/UEM, Maringá, v. 17, n. 2, 161-167, 2. Sem., 2006.

DARIDO, S. C. A educação física na escola e o processo de formação dos não praticantes de atividade física. Revista Brasileira de Educação Física e Esporte, v. 18, n. 1, p. 61-80, 2004.

FARIA JUNIOR, A. G.; CORREA, E. S.; BRESSLANE, R. S. Prática de ensino em Educação Física, estágio supervisionado. Rio de Janeiro: Guanabara, 1987.

FILGUEIRAS, I. P. et al. Concepções e preferências sobre as aulas de educação física escolar: uma análise da perspectiva discente. Revista Mackenzie de Educação Física e Esporte, São Paulo, v. 6, n. 3, p. 23-31, 2007.

FREUNDT, A. R. Los objetivos y contenidos de las actividades de expresión motriz, según la opinión de los profesores de educación física en Chile. Retos. Nuevas tendencias en Educación Física, Deporte y Recreación, Chile, v. 18, p. 56-59, 2. sem., 2010.

GAYA, A. Corpos esportivos: o esporte como campo de investigação científica. In: TANI, G.; BENTO, J. O.; PETERSEN, R. D. de S. (Eds.). Pedagogia do Desporto. Rio de Janeiro: Guanabara Koogan, 2006. p. 101-112. 
GARCIA, L. M. T.; FISBERG, M. Atividades físicas e barreiras referidas por adolescentes atendidos num serviço de saúde. Revista Brasileira de Cineantropometria e Desempenho Humano, Florianópolis, v. 13, n. 3, p. 163-169, 2011.

GARZÓN, P. C. et al. Actividad físico-deportiva em escolares adolescentes. Retos. Nuevas tendencias em Educación Física, Deporte y Recreación, v. 1, p. 5-12, 2002.

GARRIDO, M. E. G. et al. Las actividades deportivas en estudiantes de primer año medio en Osorno (Chile). Revista Internacional de Medicina y Ciencias de la Actividad Física y el Deporte, v. 11, n. 41, p. 145-163, mar., 2011.

GASTALDO, É. L. A família Scolari somos todos nós: questões de identidade brasileira na Copa de 2002. In: INTERCOM - SOCIEDADE BRASILEIRA DE ESTUDOS INTERDISCIPLINARES DA COMUNICAÇÃO XXVI CONGRESSO BRASILEIRO DE CIÊNCIAS DA COMUNICAÇÃO, 1., 2003, Belo Horizonte. Anais... Belo Horizonte: 2003. v. 1. p. 1-16.

GIL, A. C. Métodos e técnicas de pesquisa social. 6 ed. São Paulo: Atlas, 2010.

GOZZI, M. C. T.; RUETE, H. M. Identificando estilos de ensino em aulas de Educação Física em segmentos não escolares. Revista Mackenzie de Educação Física e Esporte, São Paulo, v. 5, n. 1, p. 34-49, 2006.

GOZZI, M. C. T.; RUY, M. P. Identificando estilos de ensino em aulas de Educação Física. Movimento \& Percepção, Espirito Santo do Pinhal, v. 9, n. 13, p. 360-377, jul./dez., 2008.

GUTIÉRREZ, F. G.; MARIN, J. M. D.; ORTIZ, M. N. M. Experiencias de clase en la enseñanza de la Educación Física en colegios oficiales de Bogotá. Revista Educación física y deporte, Mendellín, v. 29, n. 1, p. 23-30, 2010.

LIMA, J. DE C.; STAREPRAVO, F. A. Lazer e atividade física: perfil de escolares de 10 a 15 anos e sua relação com as políticas públicas na cidade de Pìnhão - PR. Licere, Belo Horizonte, v. 13, n. 4, p. 1-20, dez., 2010. 
MARCONI, M. DE A.; LAKATOS, E. M. Téenicas de pesquisa: planejamento e execução de pesquisas, amostragens e técnicas de pesquisas. 5. ed. São Paulo: Atlas, 2002.

MOREIRA, W. W. Apresentação. In: MOREIRA, W. W.; SIMÕES, R. (Eds.). Esporte como fator de qualidade de vida. Piracicaba: Unimep, 2002. p. 4-8.

MORENO, J. A.; RODRÍGUEZ, P. L.; GUTIÉRREZ, M. Intereses y actitudes hacia la Educación Física. Revista Española de Educación Física, v. 11, n. 2, p. 14-28, 2003.

MOSSTON, M. La enseñanza de la educacion física. Buenos Aires: Paidós, 1982.

MOURA, D. L. A educação física escolar e os estilos de ensino: uma análise de duas escolas do Rio de Janeiro. Revista Digital, v. $14 \mathrm{n}$. 137 , p. 1-7, 2009.

OLIVEIRA, S. L. Tratado de metodologia científica. 2. ed. São Paulo: Pioneira, 2002.

PAIANO, R. Possibilidades de orientação da prática pedagógica do professor de Educação Física: situações de desprazer na opinião dos alunos. Revista Mackenzie de Educação Física e Esporte, São Paulo, v. 5, n. 1, p. 47-58, 2006.

PARRACI, C. A. R. et al. Influencia de la cátedra de Educación Física frente a los estilos de vida de la población escolar del Departamento del Huila. Revista Educación física y deporte, Mendellín, v. 29, n. 1, p. $67-74,2010$.

PATRÍCIO, S. R.; SARAIVA, M. do C.; BERGERO, V. Brasil e Argentina: estudo comparativo sobre conteúdos da educação física escolar e questões de gênero. In: MATIELLO, E.; CAPELA, P.; BREILH, $\mathrm{J}$ (Eds.). Ensaios alternativos latino-americanos de educação física, esportes e saúde. Florianópolis: Copiart, 2009. p. 94-113.

PEREIRA, D. W.; ARMBRUST, I. Pedagogia da aventura: os esportes radicais, de aventura e de ação na escola. Jundiaí: Fontoura, 2010. 
PERFEITO, R. B. et al. Avaliação das aulas de educação física na percepção dos alunos de escolas públicas e particulares. Revista da Educação Física/UEM, Maringá, v. 19, n. 4, p. 489-499, 4. trim., 2008.

RODRIGUEZ, J. R.; FUENTES-GUERRA, F. J. G.; ROBLES, M. T. A. Motivos que llevan a los profesores de Educación Física a elegir los contenidos deportivos en la E.S.O. Retos. Nuevas tendencias en Educación Física, Deporte y Recreación, n. 18, p. 5-8, 2. sem., 2010.

ROSÁRIO, L. F. R.; DARIDO, S. C. (2005). A sistematização dos conteúdos da educação física na escola: a perspectiva dos professores experientes. Motriz, Rio Claro, v. 11, n. 3, p. 167-178, set./dez., 2005.

SILVA, J. V. P.; DAGOSTIN, K. U. D.; NUNEZ, P. R. M. Educação Física e conteúdos trabalhados nas séries iniciais do Ensino Fundamental. Motriz, Rio Claro, v. 1, n. 3, p. 592-599, jul./set., 2009.

SILVA, J. V. P. DA; SAMPAIO, T. M. V. Os conteúdos das aulas de Educação Física do Ensino Fundamental: O que mostram os estudos? Revista Brasileira de Ciência e Movimento, Brasília, vol. 20, n. 2, p. 106-118, 2012.

SOARES, A. J. G. et al. Tempo e espaço para educação corporal no cotidiano de uma escola pública. Movimento, Porto Alegre, v. 6, n. 1, p. 71-96, jan./mar., 2010.

SOUZA JÚNIOR, O. M.; DARIDO, S. D. Refletindo sobre a tematização do futebol na Educação Física escolar. Motriz, Rio Claro, v. 16, n. 4, 920-930, 2010.

TOMÁS, V. S. et al. La enseñanza de los deportes colectivos en Educación Física en la E. S. O. Revista Internacional de Medicina y Ciencias de la Actividad Física y el Deporte, v. 10, n. 40, p. 502-520, dez., 2010.

VALENZUELA, V. A.; BUENO, O. A. La iniciación al béisbol como alternativa a los deportes. CCD, Murcia, v. 13, n. 5, p. 96, 2010.

ZABALA, A. A prática educativa: como ensinar. Porto Alegre: Artmed, 1998. 
Recebido em: 01/12/2011

Revisado em: 16/04/2012

Aprovado em: 26/04/2012

\section{Endereço para correspondência}

jr_lazer@yahoo.com.br

Junior Vagner Pereira da Silva

Universidade Estadual de Santa Cruz

Campus Soane Nazaré de Andrade

Rodovia Jorge Amado, km 16, Bairro Salobrinho

CEP 45662-900. Ilhéus-Bahia 